\title{
СЕЗОННІ РИТМИ ОКРЕМИХ ВИДІВ РОСЛИН ЗАХИЩЕНОГО ІРУНТУ БОТАНІЧНОГО САДУ ДНІПРОВСЬКОГО НАЦІОНАЛЬНОГО УНІВЕРСИТЕТУ ІМЕНІ ОЛЕСЯ ГОНЧАРА
}

\section{І. Л. Домницька}

Ботанічний сад Дніпровсъкого національного університету імені Олеся Гончара, м. Дніпро, Україна

\begin{abstract}
Анотація. Актуальність наших досліджень зумовлено необхідністю розуміння особливостей змін сезонного росту та розвитку тропічних та субтропічних видів рослин 3 врахування змін довжини дня та мінливість грунтових умов при вирощуванні рослин у штучних умовах оранжереях. Мета роботи - проаналізувати вплив зміни умов зростання на фенологічні ритми рослин у захищеному грунті ботанічного саду Дніпровського національного університету імені Олеся Гончара. Польові та камеральні етапи досліджень проведено за загальноприйнятими методиками 3 використанням 260 таксонів тропічних та субтропічних рослин захищеного грунту ботанічного саду 3 урахуванням ритмів цвітіння та періодів повного і відносного спокою.
\end{abstract}

Встановлено, що більшість з досліджених таксонів $є$ мезофільними рослинами, батьківщиною яких є тропічні вічнозелені ліси Америки, Південно-Східної Азії, екваторіальної Африки, північно-східної області Австралії та островів Тихого океану. Показано, що періодичність розвитку окремих таксонів, окрім «генетичної» пам'яті, також пов'язана із умовами їх вирощування, терміном розмноження та додатковими агротехнічними прийомами, які здатні істотно змінювати феноритми багатьох тропічних і субтропічних рослин. Знання фенології, а також добір видів і сортів дозволить досягнути безперервного квітування колекції покритонасінних в умовах закритого грунту впродовж всього року.

Ключові слова: рослини захищеного грунту, ріст, розвиток, квітування, плодоношення.

Bcmyn. Екологічні наслідки непродуманої господарської діяльності та оптимізація стану довкілля в усьому світі є важливою проблемою $[10,12,19]$, що актуалізуе використання зелених насаджень задля оптимізації умов життедіяльності людини у промислових регіонах $[11,13,19,21]$. На відміну від рослин відкритого грунту, які безпосередньо зазнають впливу кліматичних умов конкретного

*Corresponding author. E-mail addresses: siringa65@gmail.com 
регіону $[1,6,8,18]$ та особливостей грунту, на якому вони зростають $[14,20]$, тропічні та деякі субтропічні рослини зберігаються в умовах мікроклімату оранжерей. Проте погода, як і клімат в цілому, а також його зміни значною мірою коректують екологічні умови теплиць і оранжерей $[5,7,16,17]$.

Тропічні рослини, подібно до представників флори субтропіків та помірних широт, мають ритми росту та розвитку. Зазвичай вони менш виражені та пов'язані з вологими та посушливими періодами $[3,4,9]$. Важливо враховувати зміни довжини дня та мінливість грунтових умов при вирощуванні рослин в оранжереях, які також мають значення для періодичності росту $[2-4,16]$. Ще в минулому столітті багато дослідників прийшло до висновку, що ритм росту та розвитку рослин у першу чергу обумовлений внутрішніми спадковими закономірностями рослинних організмів $[3,4,6,8]$. Зі зміною умов зовнішнього середовища змінюються і ритми життя рослин. Шляхом спрямованого впливу на рослини чинників довкілля можна деякою мірою змінювати феноритми їх розвитку у бажаному для людини напрямку. Проте на наш час наукової інформації щодо поведінки тропічних і субтропічних рослин в умовах захищеного грунту ботанічного саду Дніпровського національного університету імені Олеся Гончара є недостатньо.

Mema - проаналізувати вплив зміни умов зростання на фенологічні ритми рослин у захищеному грунті ботанічного саду Дніпровського національного університету імені Олеся Гончара.

Матеріали та методи дослідженъ. Дослідження проводились у 2016-2018 pр. в експозиційній оранжереї навчальної лабораторії тропічних і субтропічних рослин ботанічного саду Дніпровського національного університету імені Олеся Гончара.

Ботанічний сад знаходиться майже в центрі великого промислового міста Дніпро, у межах Степового Придніпров'я [15]. Оранжерея, де проводилися дослідження, на відміну від багатьох споруд такого типу, має два поверхи. Температуру вимірювали на нижньому поверсі, підраховували середньомісячну у тропічному і субтропічному відділенні. Провели порівняння з такими покажчиками за 1964-1966 роки (рослини утримувалися в одноповерховій оранжереї) [9].

Об'єктами фенологічних спостережень були 260 таксонів тропічних і субтропічних рослин. Серед них - 190 видів із різних родин, у тому числі 25 видів з родини Gesneriaceae Dumort., 70 культиварів (60 із них - сорти Saintpaulia ionantha H. Wendl.). Спостерігали виключно за рослинами, що вирощувалися в оранжереї ботанічного саду ДНУ не менше трьох років [15]. 
Результати та $\ddot{\boldsymbol{x}}$ обговорення. Досліджені феноритми 260 таксонів у захищеному грунті ботанічного саду Дніпровського національного університету імені Олеся Гончара, а також вплив змін клімату та температурного режиму оранжереї на них. Вивчені умови, за яких можливо керувати ритмами квітування для подовження його строків та покращення загального декоративного стану тропічних i субтропічних рослин.

При опрацюванні літературних джерел виявлено, що сезонні ритми, зокрема квітування Araceae Juss., Gesneriaceae Dumort., Myrtaceae Adans. та інших, так званих, кімнатних рослин у природі та культурі досліджені недостатньо $[2-4,6,17,18]$. При цьому за останні 20 років у захищеному грунті ботанічного саду Дніпровського національного університету імені Олеся Гончара і деяких інших садів України дещо змінився температурний режим. В умовах ботанічного саду Дніпровського національного університету імені Олеся Гончара факторами, що найбільш впливають на рослини колекції і при цьому найменш регулюються, є освітлення і температура в експозиційній оранжереї.

Оскільки м. Дніпро знаходиться в промисловому регіоні, на рослини захищеного грунту впливають не тільки погодні й кліматичні умови, а й значною мірою промислові викиди в повітря $[8,10,13,14,20]$, що негативно діють на всі елементи екосистем, у тому числі на здоров'я людини [14].

Експозиційна оранжерея побудована та введена в експлуатацію у 1975 р. Є дані, що вже за 10 років скло таких споруд мутнішає, що відбивається на кількості освітлення, а відтак і на температурному режимі у приміщенні [3]. У 2007-2009 рр. була проведена реконструкція даху із заміною скла на непрозорий полікарбонат, що також мало свій негативний вплив на екологічні умови і стан колекції.

Останні десятиліття в Степовому Придніпров“ї спостерігаються кліматичні зміни з підвищенням температур порівняно з нормою. За даними літературних джерел і Гідрометеослужби у Дніпропетровській області найбільші середні показники температури впродовж року спостерігаються в серпні $[10,14] .32014$ р. опалення в оранжерею поступає з середини, або кінця листопада. Хоча завдяки флуктуаціям температур в місті тепліше за умовну норму, у тропічному відділенні оранжереї середньо добова температура становила $+10,7^{\circ} \mathrm{C}$ (Рис. 1 ).

У лабораторії тропічних і субтропічних рослин упродовж багатьох років ведуться спостереження за найбільш суттєвими покажчиками екологічного середовища приміщень захищено грунту. Установлено, 
що найменші середні температури повітря $\left(+15^{\circ} \mathrm{C}\right)$ в 1999-2004 роках закономірно виявлені в січні, лютому, листопаді і грудні.

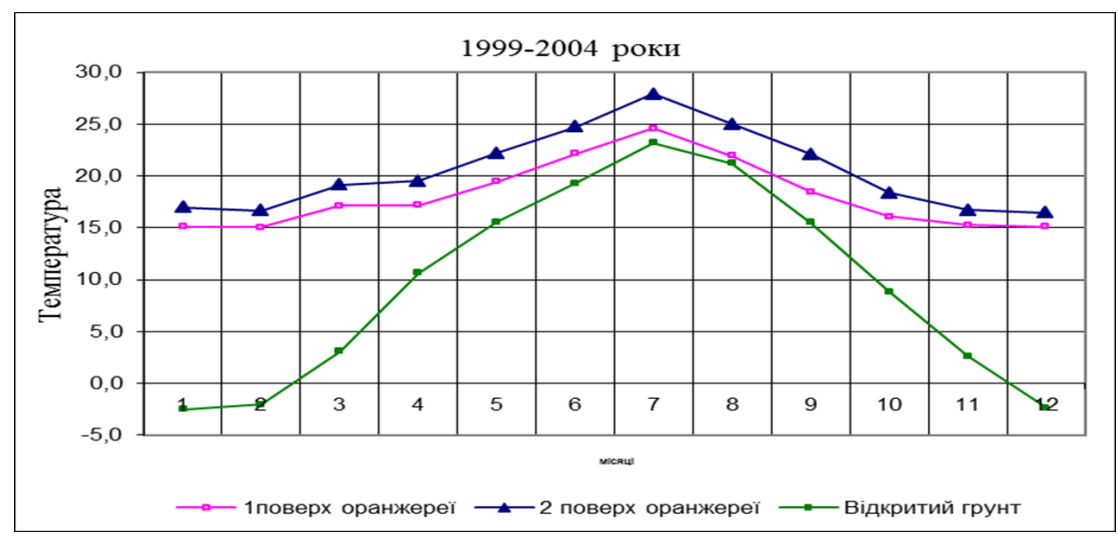

Рис. 1. Річна динаміка температур в експозиційній оранжереї ботанічного саду Дніпровського національного університету імені Олеся Гончара і у відкритиму грунті м. Дніпро

Figure 1. Annual dynamics of temperatures in the exposition greenhouse of the Botanical Garden of Oles Honchar Dnipro National University and in the open ground at Dnipro City

На нашу думку, температура нижнього поверху оранжереї, де в грунті та горщиках розміщене коріння більшості рослин, а також менша за норму для багатьох видів кількість освітлення є головними обмежуючими факторами для нормального росту та розвитку експонатів колекції (Табл. 1). Так, у 1964-1966 рр. критичні температури також спостерігались з листопада по лютий. Проте у тропічному відділу оранжереї температура повітря не була меншою за допустиму норму $\left(+16,2^{\circ} \mathrm{C}\right)$. У $2016-2018$ pр. екологічні умови оранжереї ботанічного саду Дніпровського національного університету імені Олеся Гончара дещо погіршилися. За нашими спостереженнями, лише п'ять місяців на рік рослини отримують необхідне для них тепло з атмосферного повітря. У той час як, сім місяців - з жовтня по квітень - навіть для декотрих субтропічних культур температура повітря занадто прохолодною (до $+15^{\circ} \mathrm{C}$ ). також слід зазначити, що середня відносна вологість повітря в тропічному відділі оранжереї становить $85-90 \%$, у субтропічному $73-80 \%$. 
Таблиця 1. Середньомісячні температури експозиційної оранжереї ботанічного саду Дніпровського національного університету імені Олеся Гончара за періоди 1964-1966 pp. та 2016-2018 pp., ${ }^{\circ} \mathrm{C}$

Table 1. Average monthly temperatures in the exposition greenhouse of Botanical Garden of Oles Honchar Dnipro National University during 1964-1966 and 2016-2018, ${ }^{\circ} \mathrm{C}$

\begin{tabular}{|l|c|c|c|c|c|c|c|c|c|c|c|c|}
\hline \multirow{1}{*}{$\begin{array}{c}\text { Відділи } \\
\text { оранжереї }\end{array}$} & \multicolumn{10}{|c|}{ Місяць } \\
\cline { 2 - 3 } & I & II & III & IV & V & VI & VII & VIII & IX & X & XI & XII \\
\hline Тропічний & 16,2 & 17,6 & 18,4 & 20,2 & 21,6 & 23,5 & 24,2 & 21,3 & 19,0 & 17,8 & 16,7 & 17,1 \\
\hline Субтропічний & 13,8 & 14,9 & 16,9 & 17,1 & 20,8 & 22,5 & 23,3 & 21,1 & 18,1 & 16,6 & 14,6 & 14,8 \\
\hline \multicolumn{10}{|c|}{$2016-2018$ pp. } \\
\hline Тропічний & 13,3 & 15,3 & 14,2 & 13,7 & 18,9 & 22,3 & 24,1 & 24,8 & 18,6 & 11,9 & 10,7 & 12,8 \\
\hline Субтропічний & 13,0 & 14,3 & 13,7 & 13,2 & 17,8 & 21,4 & 23,7 & 24,5 & 17,4 & 11,2 & 9,9 & 11,5 \\
\hline
\end{tabular}

Дані графіка і таблиці 1 свідчать, що найвища середня температура атмосферного повітря в приміщеннях оранжереї та у відкритому грунті, в останні роки, спостерігається в серпні. На нашу думку, цей чинник погіршуе стан рослин, таких, як Rhododendron indicum (L.) Sweet, Strelitzia reginae Banks та інші.

Суттєвою особливістю багатьох тропічних рослин є висока фенотипічна пластичність. Вони звісною мірою добре пристосовуються до змін екологічних факторів, у тому числі до різних умов вирощування в культурі. Особливо це стосується ритмів цвітіння $[3,4,6,8]$. Більшість із досліджених 260 таксонів є мезофільними рослинами, батьківщиною яких є тропічні вічнозелені ліси Америки, Південно-Східної Азї, екваторіальної Африки, північно-східної області Австралії та островів Тихого океану. Багато видів Gesneriaceae ведуть напівепіфітне життя (Saintpaulia ionantha subsp. grotei (Engl.) I. Darbysh, S. intermedia B. L. Burt), інші як петрофіти - на кам'янистих схилах - види роду Primulina Hance. Ті й інші мають ознаки суккулентних рослин потовщені листки, опушення всіх частин тіла, тощо. Achimenes grandiflora (Schiede) DC., A. longiflora (D. Dietr.) DC., види роду Kochleria Regel., Gloxinia perennis (L.) Druce зростають у місцях, де вологий сезон змінюється на сухий (Колумбія Бразилія, Перу, Мексика), тому мають підземні столони і ритми життя ефемероїдів.

Довготривалі спостереження за колекцією виявили, що в умовах оранжереї ботанічного саду Дніпровського національного університету 
імені Олеся Гончара всі види тропічних і субтропічних рослин мають періодичність росту. Найдовший період спокою приурочений до зимового сезону. Узимку недостатньо світла, низькі плюсові температури. Листопадні дерева субтропічного походження лабораторії скидають листя в жовтні-листопаді. Деякі тропічні рослини також пристосувалися до цієї ситуації. Період повного спокою займає 2-3 місяці. Тобто майже співпадає з таким у рослин помірного клімату. Також період повного спокою з повною втратою надземної частини проходять багато трав'янистих рослин: усі представники роду Achimenes, Gloxinia perennis (L.) Druce, Sinningia speciosa (Lodd.) Hiern. та її гібриди, Amorphophallus konjac K. Koch, Zantedeschia albo-maculata (Hook. f.) Bailey, Z. aethiopica (L.) Spreng, Crinum moorei Hook. f., Scadoxus multiflorus subsp. katharinae (Baker) Friis \& Nordal.

Після заміни скляного даху на полікарбонат (2009 р.) в одних рослин piзко, у інших поступово змінилися ритми цвітіння. Так, у Ficus sinuata Thunb. повне забарвлення сіконіїв до 2007 року стабільно спостерігалося від 22 грудня по 7 січня. Після заміни даху воно поступово змінювало дати, поки не стабілізувалося у липні. За таких умов останні роки майже не квітують: Achimenes grandiflora (Schiede) DC., A. longiflora (D. Dietr.) DC., A. coccinea DC., Hibiscus rosa-sinensis, Zantedeschia albomaculata (Hook. f.) Bailey, більшість кактусів і сукулентів. 32009 року не цвіте найстаріший екземпляр колекції Hibiscus rosa-sinensis L.

Рік у рік різні рослини виходять зі спокою в різні строки. Але в середині лютого - на початку березня більшість колекції починає рости. Початок росту перш за все пов'язаний зі світлом і температурою. У деяких рослин значну роль має полив. У колекції оранжереї ботанічного саду Дніпровського національного університету імені Олеся Гончара $\epsilon$ види рослини з періодом спокою влітку: представники південноафриканської флори: Amarillidaceae J. St.-Hil., Crassulaceae J. St.-Hil., Euphorbiaceae Juss., Strelitziaceae Huntch.

За результатами наших спостережень, серед 260 таксонів колекційного фонду оранжереї постійного спостереження квітують 255, плодоносять 175 (Табл. 2). Найбільша кількість квітучих видів тропічного походження припадає на березень-травень, максимум цвітіння - на квітень-червень. У разі підвищення температури, кількість квітучих видів швидко скорочується. При цьому, деякі види квітують удруге у серпні-жовтні.

Узимку цвіте багато видів південно-африканського походження: сукуленти, Strelitzia reginae Banks, Zantedeschia aethiopica (L.) Spreng, Sparmannia africana L. 
Таблиця 2. Кількість по місяцях квітучих видів різного географічного походження в оранжереї ботанічного саду Дніпровського національного університету імені Олеся Гончара впродовж 2016-2018 pp.

Table 2. The number by months of different geographical origin of flowering species in the greenhouse of the Botanical Garden of Oles Honchar Dnipro National University during 2016-2018

\begin{tabular}{|l|c|c|c|c|c|c|c|c|c|c|c|c|}
\hline \multirow{2}{*}{ Походження } & \multicolumn{10}{|c|}{ Місяць } \\
\cline { 2 - 15 } & I & II & III & IV & V & VI & VII & VIII & IX & X & XI & XII \\
\hline $\begin{array}{l}\text { Південна } \\
\text { Америка }\end{array}$ & 14 & 7 & 16 & 17 & 20 & 19 & 17 & 15 & 10 & 10 & 7 & 7 \\
\hline Африка & 6 & 15 & 15 & 18 & 25 & 17 & 16 & 12 & 10 & 6 & 6 & 6 \\
\hline $\begin{array}{l}\text { Південно- } \\
\text { східна Азія }\end{array}$ & 10 & 14 & 13 & 10 & 10 & 10 & 8 & 7 & 6 & 4 & 4 & 2 \\
\hline $\begin{array}{l}\text { Центральна } \\
\text { Америка та } \\
\text { Мексика }\end{array}$ & 2 & 3 & 5 & 8 & 10 & 8 & 8 & 7 & 1 & 2 & 2 & 2 \\
\hline $\begin{array}{l}\text { Австралія, } \\
\text { Нова Зеландія }\end{array}$ & - & 2 & 3 & 3 & 5 & 4 & 2 & 1 & 1 & 1 & - & - \\
\hline $\begin{array}{l}\text { Середземно- } \\
\text { мор'я }\end{array}$ & 2 & 3 & 3 & 3 & 4 & 4 & 4 & 3 & 3 & 2 & 1 & - \\
\hline Індія & 1 & 1 & 4 & 5 & 8 & 4 & 4 & 3 & 1 & 1 & - & 1 \\
\hline Мадагаскар & 2 & 7 & 6 & 4 & 4 & 3 & 3 & 2 & 2 & 2 & 1 & 1 \\
\hline Разом & 37 & 52 & 55 & 68 & 86 & 69 & 62 & 50 & 34 & 28 & 21 & 19 \\
\hline
\end{tabular}

Масове цвітіння спостерігається у Rhododendron indicum (L.) Sweet, Bilbergia nutans Wendl. Менше цвітуть, ніж в інші місяці, представники Південно-східної Африки: Saintpaulia H. Wendl. Тривалість квітування у більшості видів - близько одного місяця. Інколи - два-три. Окремі види цвітуть від 4 до 8 місяців: Abutilon sellowianum (Klotzsch) Regel, Jasminum sambac (L.) Aiton, всі види Kohleria, види та сорти Saintpaulia.

Аналіз спостережень за тропічними і субтропічними рослинами оранжереї дозволяе виділити фенологічно стійкі і нестійкі види. До першої групи відносять види, які зберегли той же ритм розвитку, що й у країні походження. Приклад - рослини зимового квітування, ті, що мають період спокою влітку, а також багато субтропічних видів північної півкулі. Виняток - Eriobotria japonica (Thunb.) Lindl., плоди якої у природних умовах достигають у травні-червні, у захищеному грунті м. Дніпро - в березні-квітні. Друга група - види, 
що змінили в нових умовах ритм розвитку. У них спостерігається сильні відхилення окремих фаз розвитку від середніх дат. Серед них декотрі представники тропіків південної півкулі, наприклад: Kohleria amabilis (Planch et Linden) Fritsch var. bogotensis (G. Nicholson) LP. Kvist et L. E. Skog., K. eriantha (Benth.) Hanst., Sinningia speciosa Hierh. Вони чутливо реагують на зміни температур, освітлення, вологи повітря та грунтів. Найбільший вплив на феноритми Gesneriaceae мають строки розмноження.

Висновки. Досліджені феноритми 260 таксонів у захищеному грунті ботанічного саду Дніпровського національного університету імені Олеся Гончара, а також вплив змін клімату та температурного режиму оранжереї на них. Установлено, що всі види тропічних і субтропічних рослин ботанічного саду мають детерміновану періодичність розвитку.

Періодичність розвитку окремих видів пов'язана з умовами їх вирощування, терміном розмноження та додатковими агротехнічними прийомами, які здатні істотно змінювати феноритми багатьох тропічних і субтропічних рослин. Знання фенології, а також добір видів і сортів дозволить досягнути безперервного квітування колекції покритонасінних в умовах закритого грунту впродовж всього року.

\section{Reference}

1. Andrusevich, K. V., Nazarenko, M. M., Lykholat, T. Yu., \& Grigoryuk, I. P. (2018). Effect of traditional agriculture technology on communities of soil invertebrates. Ukrainian journal of Ecology, 8 (1), 33-40. https://doi.org/10.15421/2017_184

2. Bahuguna, R. N., \& Jagadish, K. S. V. (2015). Temperature regulation of plant phenological development. Environmental and Experimental Botany, 111, 83-90. https://doi.org/10.1016/j.envexpbot.2014.10.007

3. Gornitskaya, I. P. (1995). Introdukciya tropicheskih i subtropicheskih rastenij, ee teoreticheskie $i$ prakticheskie aspekty [Theoretic and practice aspects of introduction of tropical and subtropical plants]. Donetchina. (in Russian).

4. Gornitskaya, I.P., \& Tcachuk, L.P. (2008). Teoreticheskiye voprosy introdukcii tropicheskih $i$ subtropicheskih rastenij [Theoretic aspects of introduction of tropical and subtropical plants]. Veber. (in Russian).

5. Domnitskaya, I. L. (2010). Izmenchivost sesonnyh ritmov razvitiya gesnerievih (Gesneriaceae Dumort.) s zapasayuschimi organami v usloviyah zakritoho grunta botanicheskoho sada Dnepropetrovskoho 
nacyonalnoho universiteta [Seasonal rhythms variability of development of Gesneriaceae Dumort. with stocking organs in the conditions of the closed soil in Botanical Garden of Dnepropetrovsk National University]. Byulleten Nikitskogo botanicheskogo sada [Bulletin of Nikitsky botanic gardens], 101, 23-26. (on Russian).

6. Domnitskaya, I. L. (2017). Sorta roda Saintpaulia H. WENDL. v zaschischYonnom grunte botanicheskogo sada DNU [The cultivars of Saintpaulia H. wendl. in the protected soil of botanical garden DNU]. Pytannia stepovoho lisoznavstva ta lisovoi rekultyvatsii zemel [Issues of steppe forestry and forest reclamation of soils], 46, 28-34. https://doi.org/10.15421/441705 (in Russian).

7. Domnitskaya, I. L. (2018). Morfometricheskie i biologicheskie pokazateli pri opredelenii dekorativnosti predstaviteley roda Saintpaulia H. WENDL [Morphometrical and biological indicators in definition decorative representatives to the Saintpaulia H. WENDL.]. Pytannia stepovoho lisoznavstva ta lisovoi rekultyvatsii zemel [Issues of steppe forestry and forest reclamation of soils], 47, 49-54. https://doi.org/10.15421/441806 (in Russian).

8. Domnitskaya, I. L. (2019). Kompleksnaya otsenka sortov roda Saintpaulia H. WENDL., introdutsirovannyih v zaschischYonnyiy grunt botanicheskogo sada Dneprovskogo natsionalnogo universiteta imeni Olesya Gonchara [The complex estimation of cultivars of Saintpaulia H. WENDL. in the protected soil of botanical garden of Oles Hohchar Dnipro national university]. Lisove i sadovo-parkove hospodarstvo [Forestry and landscape gardening], 15. Retrieved from http://journals.nubip.edu.ua/index.php/Lis/article/view/8982/11817 (in Russian).

9. Koverya, S. (1971). O fenolohicheskyh ritmah orangerejnyh rastenyy botanycheskogo sada Dnepropetrovskogo gosuniversiteta. [On the phenological rhythms of greenhouse plants of the Botanical Garden of Dnipropetrovsk University]. Introdukciya rasteniy $v$ Dnepropetrovskom botanicheskom sadu Dnepropetrovsk Ukraine [Plant introduction in the botanical garden of Dnipropetrovsk State University], 60-64. (in Russian).

10. Lykholat, Yu. V., Khromykh, N. O., Ivan'ko, I. A., Matyukha, V.L., Kravets, S.S., Didur, O.O., Alexeyeva, A. A., \& Shupranova, L. V. (2017). Assessment and prediction of the invasiveness of some alien 
plants in conditions of climate change in the steppe Dnieper region. Biosystems Diversity, 25 (1), 52-59. https://doi.org/10.15421/011708

11. Lykholat, T. Yu., Lykholat, O. A., Marenkov, O. M., Kulbachko, Yu. L., Kovalenko, I. M., \& Didur, O. O. (2019). Xeneostrogenes influence on cholinergic regulation in female rats of different age. Ukrainian Journal of Ecology, 9 (1), 240-243.

12. Lykholat, Y.V., Khromykh, N. O., Lykholat, T. Yu., Didur, O. O., Lykholat, O. A., Legostaeva, T. V., Kabar, A. M., Sklyar, T. V., Savosko, V. M., Kovalenko, I. M., Davydov, V. R., Bielyk, Yu. V., Volyanik, K. O., Onopa, A. V., Dudkina, K. A., \& Grygoryuk, I. P. (2019). Industrial characteristics and consumer properties of Chaenomeles Lindl. Fruits. Ukrainian Journal of Ecology, 9 (3). 132-137.

13. Lykholat, Yu. V., Khromykh, N. O., \& Alexeyeva, A. A. (2019). Stan invaziinosti Ulmus Pumila L. v urboekosystemi za klimatychnykh zmin [Condition of invasiveness of Ulmus pumila L. in urboecosystem because of climatic changes]. Ekolohichnyi visnyk Kryvorizhzhia [Ecological Bulletin of Kryvyi Rih District], 4, 7-21. https://doi.org/10.31812/ecobulletin-krd.v4i0.2525 (in Ukrainian).

14. Lykholat, Yu. V., Khromykh, N. O., Didur, O. O., Okovytyy, S. I., Matyukha, V.L., Savosko, V. M., Lykholat, T. Yu. (2019). Suchasnyi stan antropohennoi transformatsii ekosystem stepovoho Prydniprovia [The current state of anthropogenic transformation of the steppe Dnieper' ecosystems]. Publishing house Cherniavskyi D. (in Ukrainian).

15. Opanasenko, V.F., Kabar, A. N., Martynova, N.V., Rusetzkaya, L. L., Domnitskaya, I. L., Bilyk, I. V., Lomyga, L. L., \& Zamyatina, L.P. (2015). Katalog rasteniy botanicheskogo sada Dnepropetrovskogo natsionalnogo universiteta imeni Olesya Gonchara [Plant Catalogue of Oles Gonchar Dnepropetrovsk National University Botanic Garden]. Lira. (in Russian).

16. Pertseva, T.A., Lykholat, E. A., \& Gurzhiy, E. V. (2008). Vliyanie tiotropiya bromida na sostoyanie mukociliarnogo klirensa u bol'nyh hronicheskim obstruktivnym zabolevaniem legkih. [The influence of tiotropium bromide on mucociliary clearance's condition in patients with chronic obstructive pulmonary disease]. Ukrainian Pulmonology Journal, 1, 13-15. (in Ukrainian).

17. Polonskaya, A.K., Galuschko, R. V., \& Gerasimchuk, V. N. (2006). Biochimicheskiy potencial plodov i vegetativnih organov Eriobotrya japonica (Thunb.) Lindl. v usloviyah Yujnogo berega Krima. 
[Biochemical potential of fruits end vegetative organs Eriobotrya japonica (Thunb.) Lindl. in the conditions of the Southern coast of Crimea]. Byulleten Nikitskogo botanicheskogo sada [Bulletin of Nikitsky botanic gardens], 92, 30-34. (in Russian).

18. Borchert, R., Robertson, K., Schwartz, M., \& WilliamsLinera, G. (2005). Phenology of temperate trees in tropical climates. International journal of Biometeorology, 50 (1), 57-65. https://doi.org/10.1007/s00484-005-0261-7

19. Savosko, V. M., \& Tovstolyak, N. V. (2017). Ecological conditions of garden and park territories of former iron mines (Kryvyi Rih Basin, Ukraine). Ukrainian Journal of Ecology, 7 (4), 12-17.

20. Savosko, V. M., Lykholat, Yu. V., Bielyk, Yu. V., \& Lykholat, T. Yu. (2019). Ecological and geological determination of the initial pedogenesis on devastated lands in the Kryvyi Rih Iron Mining \& Metallurgical District (Ukraine). Journal of Geology, Geography and Geoecology, 28 (4), 738-746. https://doi.org/10.15421/111969

21. Savosko, V., Lykholat, Yu., Domshyna, K., \& Lykholat, T. (2018). Ekolohichna ta heolohichna zumovlenist poshyrennia derev i chaharnykiv na devastovanykh zemliakh Kryvorizhzhia [Ecological and geological determination of trees and shrubs' dispersal on the devastated lands at Kryvorizhya]. Journal of Geology, Geography and Geoecology, 27 (1), 116-130, https://doi.org/10.15421/111837

\title{
SEASONAL RHYTHMS OF SOME PLANTS SPECIES AT BOTANICAL GARDEN PROTECTED GROUND OF OLES HONCHAR DNIPRO NATIONAL UNIVERSITY
}

\section{L. Domnitskaya}

Botanical Garden of Oles Honchar Dnipro National University, Dnipro, Ukraine

\begin{abstract}
The relevance of our research is due to the need to understand the main features of changes in seasonal growth and development of tropical / subtropical plant species. It is also important to take into account changes in day length and variability of soil conditions when growing plants in greenhouses. The object of our paper to analyze the impact of changes in growth conditions on the phenological rhythms of plants in greenhouses of the botanical garden of the Oles Honchar Dnipro National University. Field and in-house stages of our research were carried out according to generally accepted methods using 260 taxa of tropical and subtropical plants, taking into account the rhythms of flowering and periods of complete and relative rest.

It has been established that most of the taxa we studied are mesophilic plants. Their homeland is the tropical evergreen forests of America, Southeast Asia,
\end{abstract}


equatorial Africa, the northeastern region of Australia and the Pacific Islands. In the greenhouse of the Botanical Garden of the Oles Honchar Dnipro National University, the growth and development of these plants is very difficult. The results of our research have convincingly proved that all species of tropical and subtropical plants have a determined periodicity of their development. With the frequency of development of individual species is associated with the conditions of their cultivation, the period of reproduction and additional agronomic techniques. These factors can significantly change the phenorhythms of many species of tropical and subtropical plants. Analysis of observations of tropical and subtropical plants allows to distinguish phenologically stable and phenologically unstable plant species. The first group (phenological runoff) includes plant species that have maintained the same rhythm of development as in the country of origin. The second group (phenologically unstable) is represented by plant species that have changed the rhythm of development in the new conditions. They have strong deviations of certain phenological phases of development from the average dates.

In general, the frequency of development of individual taxa, in addition to "genetic" memory, is also associated with the conditions of their cultivation, the period of reproduction and additional agronomic techniques. They are able to significantly change the phenorhythms of many tropical and subtropical plant species. Knowledge of phenology, as well as the selection of species and varieties will achieve continuous flowering of the angiosperm collection in closed soil throughout the year.

Keywords: plants of protected soil, growth, development, flowering, fruiting.

\section{Citation as:}

Domnitskaya, I. L. (2020). Sezonni rytmy okremykh vydiv roslyn zakhyshchenoho gruntu botanichnoho sadu Dniprovskoho natsionalnoho universytetu imeni Olesia Honchara [Seasonal rhythms APA of some plants species in the greenhouse of the Botanical garden of Oles Honchar Dnipro National University]. Ekolohichnyi visnyk Kryvorizhzhia [Ecological Bulletin of Kryvyi Rih District], 5, 155-166. https://doi.org/10.31812/eco-bulletin-krd.v5i0.4362.

Домницька І. Л. Сезонні ритми окремих видів рослин захищеного грунту ботанічного саду Дніпровського національного 8302:2015 університету імені Олеся Гончара. Екологічний Вісник Криворіжсжя. 2020. Вип. 5. С. 155-166. 